Kalamatika: Jurnal Pendidikan Matematika

Volume 6, No. 1, April 2021, pages 71-82

\title{
ANALYSIS OF MATHEMATICAL WRITING ERRORS RELATED TO THE ANGLE OF TRIGONOMETRY FUNCTIONS
}

\author{
Budi Mulyono 1, Hapizah² \\ ${ }^{1,2}$ Universitas Sriwijaya, Palembang, Indonesia \\ budimulyono.unsri@gmail.com \\ hapizah@fkip.unsri.ac.id
}

\begin{abstract}
Mathematical writing errors are often made by students, especially when writing mathematical expressions on the angle of trigonometric functions. One of the causes of this error is that students do not pay close attention to the difference between radians and degrees when writing questions or writing answers. These mathematical writing errors were made mainly by students who were oriented towards the result of the answer to a question, without paying attention to good and correct writing rules. One form of writing errors in mathematical expressions of trigonometric functions is writing $\mathrm{y}=\sin (\mathrm{x}+45)$, which is considered the same as writing $\mathrm{y}=$ $\sin \left(x+45^{\circ}\right)$. If they are asked to compare the graphical form of the function of the two mathematical expressions in the same image, the writing error will be recognized and seen. Counterexamples and technology in learning mathematics can help students understand and correct errors in writing mathematical expressions of trigonometric functions.
\end{abstract}

\section{ARTICLE INFORMATION}

Keywords Article History

MathematicalExpressions

Submitted Dec 1, 2020

Writing errors

Revised Apr 4, 2021

Trigonometry Functions

Accepted Apr 5, 2021

The angle of Trigonometry Functions

\section{Corresponding Author}

Budi Mulyono

Universitas Sriwijaya

Palembang, Indonesia

Email: budimulyono.unsri@gmail.com

\section{How to Cite}

Mulyono, B, \& Hapizah.(2021). Analysis of Mathematical Writing Errors Expression Related to the Angle of Trigonometry Functions. Kalamatika: Jurnal Pendidikan Matematika, 6(1), 71-82.

https://doi.org/10.22236/KALAMATIKA.vol6no1.2021pp71-82 


\section{INTRODUCTION}

Mathematics is formed from symbols that can be combined to make statements about the world around us (Brown, 2017). A combination of symbols that can assign numbers, constants, variables, mathematical operations, brackets, and other symbols is called a mathematical expression (Banfill, 2012). Writing mathematical expressions properly and correctly according to the rules is very important to not cause misunderstanding for those who read or learn the mathematical concepts that are being discussed.

Writing mathematical symbols that do not match the rules will cause errors in interpreting the mathematical sentences. One of the errors identified when solving a problem is in writing mathematical symbols (Irfan, 2017). This indicates that students should have the ability to understand and write mathematical symbols properly and correctly to solve problems because this ability will be related to mathematical modeling that is made as a solution to the problem-solving problem.

Errors in writing mathematical symbols in solving the problems given by students could be because students tend to be oriented towards the end result so that they only try to remember the complete procedure without understanding the mathematical concepts they have learned properly. Understanding a mathematical concept that is not comprehensive or only partial understanding will lead to misconceptions about the concept (Mulyono and Hapizah, 2017). According to Allen (2007), misconceptions must be deconstructed, and teachers must help students reconstruct the correct concepts. Counterexamples are very helpful in confronting students with their misconceptions (Allen, 2007).

One of the prerequisite materials for the differential calculus course is trigonometric functions. Mastering the prerequisite material is critical to understand new concepts that will be studied next.

\section{METHOD}

Identifying errors in writing mathematical expressions was done by observing student answers to problems about trigonometric functions. Students whose answers used as objects of observation were mathematics education students at a tertiary institution in South Sumatra. The identification of errors, in this case, did not focus on how many students were making mistakes but rather to the presence or absence of errors made by students in writing mathematical expressions on trigonometric functions. Furthermore, the answers containing the 
errors in writing mathematical expressions of trigonometric functions were analyzed descriptively.

The identification results show that the writing of mathematical expressions that do not conform to the rules was sometimes done by students intentionally or unintentionally. This happened because when students wrote answers to these questions, they were only oriented towards the final result without paying attention to the rules of writing mathematical expressions properly. If this is done continuously, it might cause a misunderstanding of the mathematical concepts studied.

One of the most common errors in writing mathematical expressions is related to the form of angular units in trigonometric functions. This is because students consider writing degrees or not writing degrees, the final result remains the same. One example of misunderstanding that students experienced is that they assumed that $\sin 45^{\circ}=\frac{1}{2} \sqrt{2}$ and $\sin 45=\frac{1}{2} \sqrt{2}$

\section{RESULT AND DISCUSSION}

Trigonometry recognizes two angular units used to determine the value of a trigonometric function: degrees and radians. It is known that $180^{\circ}=\pi$ radian. in the trigonometric questions given to students, some used radian units. Students who were accustomed to using radian units would not experience problems writing their answer solutions in mathematical expressions in the form of radians. However, for some students who were not familiar with it, they changed the form of the radians in units of degrees; for example, angles with quantities $\frac{\pi}{4}$ would be transformed into $45^{\circ}$. So when they were asked to determine the value of $\sin \frac{\pi}{4}$, then they would provide the following solutions: $\sin \frac{\pi}{4}=\sin 45^{\circ}=\frac{1}{2} \sqrt{2}$, as in Figure 1 . 


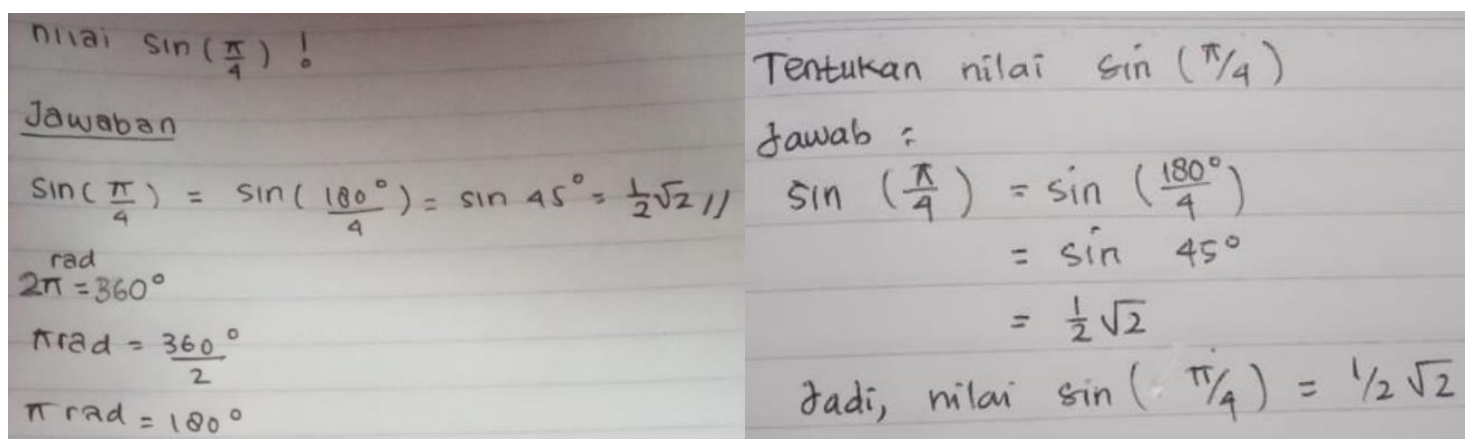

Figure 1. Snippets of Student Answers

Students often made errors by not writing the degree unit symbol at the solution; they only wrote it down, $\sin \frac{\pi}{4}=\sin 45=\frac{1}{2} \sqrt{2}$, as shown in Figure 2 .

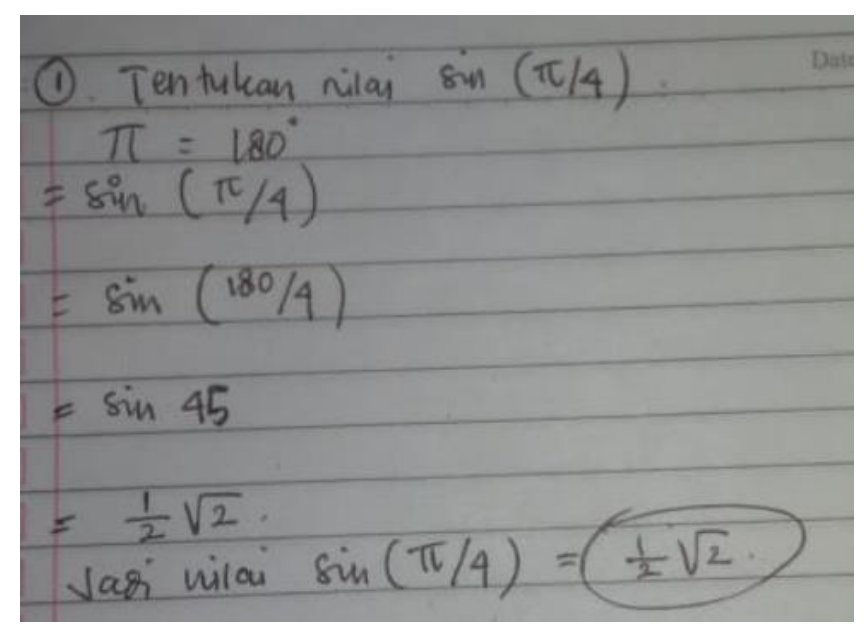

Figure 2. Snippets of Student Answers

Although writing the solutions in form $\sin \frac{\pi}{4}=\sin 45^{\circ}=\frac{1}{2} \sqrt{2}$ and in form $\sin \frac{\pi}{4}=\sin 45=\frac{1}{2} \sqrt{2}$ gave the same final result, students should not make mistakes in writing expressions like $\sin \frac{\pi}{4}=\sin 45$.

Writing errors, such as $\sin \frac{\pi}{4}=\sin 45 X$, were not realized by students since they did not see the difference in the final results they got. However, this will not happen if they were asked to graph the functions $y=\sin \left(x+\frac{\pi}{4}\right), y=\sin \left(x+45^{\circ}\right)$, and $y=\sin (x+45)$ in the same 
image area. With the help of one of the dynamic geometry softwares, Geogebra, the three graphs of the trigonometric functions can be easily created, as shown in Figure 3.

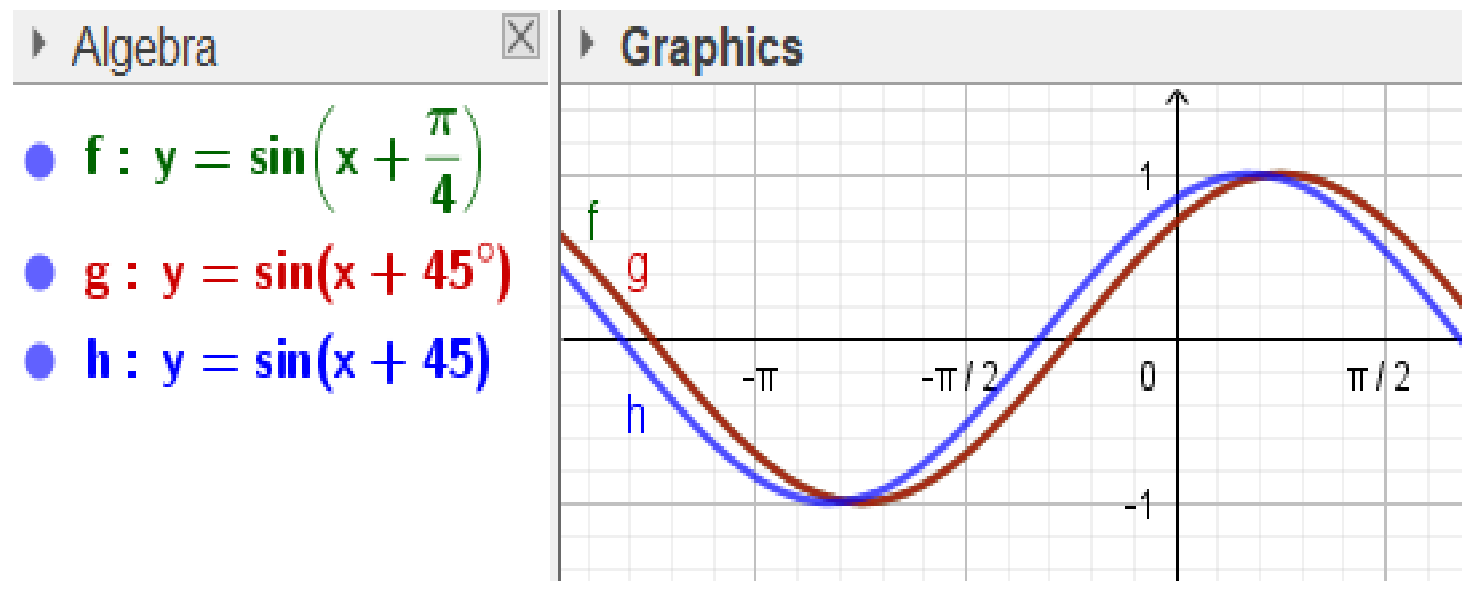

Figure 3. Comparison of Trigonometric Function Graph Forms

Based on the graph of the three trigonometric functions in Figure 3, students can see that the graph of $y=\sin \left(x+\frac{\pi}{4}\right)$ coincides with the graph of $y=\sin \left(x+45^{\circ}\right)$, while the graph of $y=\sin (x+45)$ does not coincide with the other graphs. This shows students that wrote $y=\sin \left(x+45^{\circ}\right)$ has a different meaning and result with those who wrote $y=\sin (x+45)$. Thus, students will realize that writing a mathematical expression of the angular magnitude of the trigonometric function must be correct

If the errors in writing the mathematical expression of the trigonometric function are not corrected, and it is not considered an important problem, this will lead to a misunderstanding or misconception, that is, students will think that the writing of the degree magnitude symbol is not important. So when they get a question that asks the value of cos60, they will give an answer that the value of $\cos 60=\frac{1}{2}$, because they as sume that $60=60^{\circ}$, as shown in Figure 4. 


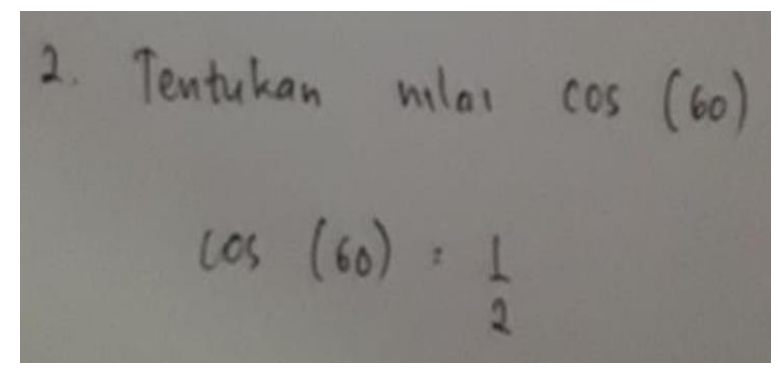

(a)

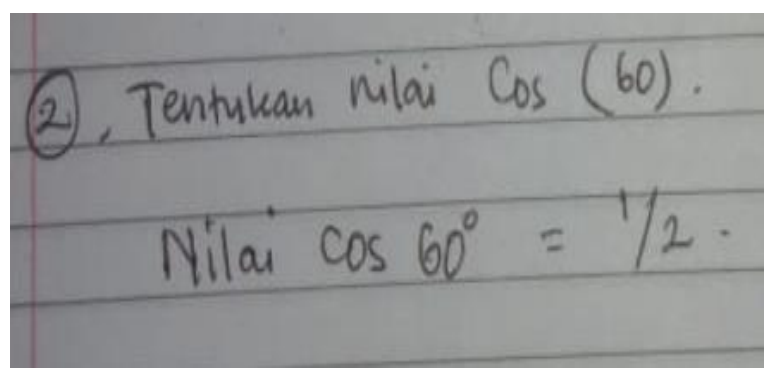

(b)

Figure 4. Snippets of Student Answers

The student's answer in Figure 4 (a) indicates that the student had an understanding that $\cos 60=\frac{1}{2}$, because in the student's memory, the value of $\cos 60^{\circ}=\frac{1}{2}$, even though the student did not write the angular unit in degrees in the answer. This assumption can be seen from the answers of other students in Figure 4 (b), who wrote down the angle unit in degrees, which shows their understanding, which was $\cos 60=\cos 60^{\circ}=\frac{1}{2}$.

One way to correct a misunderstanding of a mathematical concept is by giving a question or counterexamples. According to Rollins (2020), counterexamples are very helpful because they allow one to easily and quickly show that an idea or thought is wrong. Giving assignments to describe graphs of the functions $y=\sin \left(x+\frac{\pi}{4}\right), y=\sin \left(x+45^{\circ}\right) \circ$, and $y=\sin (x+45)$ in the same image area is an example of counterexamples for students who have an understanding of $y=\sin \left(x+45^{\circ}\right)$ is the same as $y=\sin (x+45)$.

In addition to the use of dynamic geometry software in mathematics learning, scientific calculators can also be used as a medium to help show the difference between $\sin 30$ and $\sin 30^{\circ}$ values. Designing questions that simultaneously ask for $\sin 30$ and $\sin 30^{\circ}$ values, will provide a kind of trigger for students to think about the different results they will get, as shown in Figure 5. 


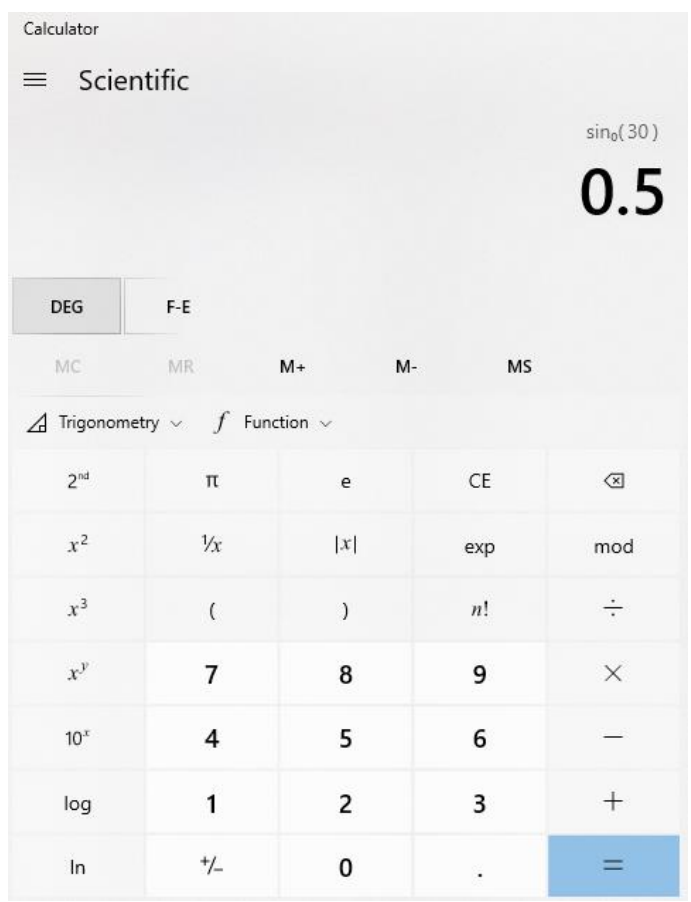

(a)
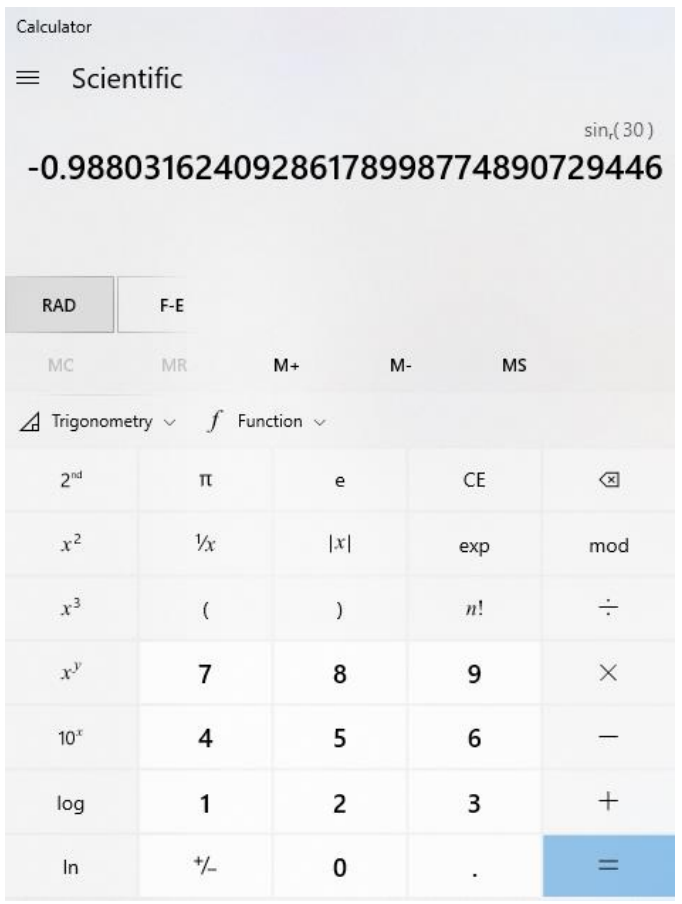

(b)

Figure 5. Values of $\sin 30^{\circ}$ and $\sin 30$ trigonometric functions

Figure 5 (a) shows the calculation result of the value of $\sin 30$ with the angle unit setting (DEG), while Figure 5 (b) shows the calculation result of the value of sin 30 with the angle unit setting of radians (RAD). Based on the calculation results, students will realize and understand that writing the mathematical expression of $\sin 30$ is not the same in meaning and value as writing the mathematical expression of $\sin 30^{\circ}$. At this stage, students have realized and corrected their misunderstanding of the angular unit of a trigonometric function.

Teachers play a great role to correct and minimize students' errors in writing mathematical expressions. One of them is by designing questions or problems that train procedural skills in counting and make students think critically about the answers. The following sample problems can be used as a reference for designing other problems.

1. Use a scientific calculator to determine the values of the following trigonometric functions:
a) $\sin 60^{\circ}$
b) $\sin 60$
c) $\sin \frac{\pi}{3}$
d) Is $\sin 60^{\circ}$ the same as $\sin 60$ ? Give the reason. 
e) Is $\sin 60^{\circ}$ the same as $\sin \frac{\pi}{3}$ ? Give the reason.

f) Is $\sin 60$ the same as $\sin \frac{\pi}{3} ?$ Give the reason.

g) Is writing the angle unit properly and correctly is important? Give the reason.

2. Use the GeoGebra application to graph the following trigonometric functions on a single image area:
a) $y=\tan \left(x+45^{\circ}\right)$
b) $y=\tan (x+45)$
c) $y=\tan \left(x+\frac{\pi}{4}\right)$

d) Is the graph of $y=\tan \left(x+45^{\circ}\right)$ the same as the graph of $y=\tan (x+45)$ ? Give the reason.

e) Is the graph of $y=\tan \left(x+45^{\circ}\right)$ the same as the graph of $y=\tan \left(x+\frac{\pi}{4}\right)$ ? Give the reason.

f) Is the graph of $y=\tan (x+45)$ the same as the graph of $y=\tan \left(x+\frac{\pi}{4}\right)$ ? Give the reason.

g) Is writing the angular unit of the trigonometric function correctly and correctly important? Give the reason.

Both examples of the questions have a question structure that aims to make students:

1. Able to perform procedures to calculate values and draw graphs of trigonometric functions using scientific calculators and the Geogebra application.

2. See the difference in the value of the function and the graph of the trigonometric function from the results they obtain.

3. See the similarity of function values and graph of trigonometric functions from the results they get.

4. Understand the value of trigonometric functions is influenced by the angle unit. 
5. Understand that writing the angle unit of the trigonometric function properly and correctly is important.

The use of scientific calculators and the GeoGebra application is one of the uses of technology in learning mathematics. Many opinions support the need for innovative mathematics learning design aided by technology. According to Garner \& Garner (2001), one of the main points of the calculus renewal movement is the use of technology (computers and calculators), and technology has an impact on learning mathematics for various reasons, mainly because the technological development is very fast. According to Liang (2016), using technology in the form of a graphing calculator supports an interactive, dynamic, and persuasive approach to teaching limits. According to Stols (2007), the latest technologies can help students visualize difficult-to-understand concepts and help to form an active problemsolving environment. According to Bhalla (2013), teachers who are equipped with computerassisted multimedia content to explain lesson topics teach better and make the teaching and learning process fun, interesting, and easy to understand. Thompson et al. (2013) stated that a radical reconstruction of calculus ideas is possible by using computational technology. The teacher is the key to the successful use of technology in the mathematics classroom but incorporating technology into teaching remains a challenge for many teachers (Drijvers et al., 2014).

\section{CONCLUSION}

This study concluded that writing errors as described above can cause a misunderstanding of the angular unit in trigonometric functions if not corrected as early as possible. Therefore, giving counterexamples will help correct and minimize errors in writing mathematical expressions of trigonometric functions and avoid misunderstandings of angular units in trigonometric functions. Besides, using scientific calculators to calculate the forms of mathematical expressions of trigonometric functions can help students understand the differences in the values of trigonometric functions that they initially consider the same. Also, the use of dynamic geometry software, in this case, GeoGebra, to graph the forms of mathematical expressions of trigonometric functions is another way to help students visually understand the differences in graphs of trigonometric functions which they initially consider to be the same. 


\section{REFERENCES}

Allen, G.D. (2007). Student Thinking. College Station: Texas A\&M.

Banfill, J. (2012). Definition relating to expressions. https://www.aaamath.com

Bhalla, J. (2013). Computer Use by School Teachers in Teaching-learning Process. Journal of Education and Training Studies. Vol. 1, No. 2. ISSN 2324-805X E-ISSN 2324-8068. Published by Redfame Publishing.

Brown, N. (2017). What Is a Mathematical Expression? https://sciencing.com

Garner, B.E., dan Garner, L.E. (2001). Retention of Concepts and Skills in Traditional and Reformed Applied Calculus. Mathematics Education Research Journal 2001, Vol. 13, No.3, 165-184.

Irfan, M. (2017). Analisis Kesalahan Siswa dalam Pemecahan Masalah Berdasarkan Kecemasan Belajar Matematika. Jurnal Matematika Kreatif-Inovatif (Kreano). Volume 8 No 2, Halaman: 143-149. p-ISSN: 2086-2334; e-ISSN:2442-4218.

Liang, S. (2016). Teaching the Concept of Limit by Using Conceptual Conflict Strategy and Desmos Graphing Calculator. International Journal of Research in Education and Science. (IJRES), 2(1), 35-48.

Mulyono, B., dan Hapizah. (2017). Does Conceptual Understanding of Limit Partially Lead Students to Misconceptions? Journal of Physics: Conference Series, Vol 895, Issue 1.

Paul Drijvers, John Monaghan, Mike Thomas, Luc Trouche. Use of Technology in Secondary Mathematics: Final Report for the International Baccalaureate. [Research Report] International Baccalaureate. 2014. pp: 01546747

Rollins. B. (2020). Counterexample in Math: Definition \& Examples. Study.com.

Stols, G. (2007). Designing Mathematical-Technological Activities for Teachers Using the Technology Acceptance Model. Journal Pythagoras, Volume 65, pp. 10-17 
Thompson, et al. (2013). A Conceptual Approach to Calculus Made Possible by Technology. Computers in the Schools, 30:124-147, 2013. Copyright (C) Taylor \& Francis Group, LLC. ISSN: 0738-0569 print / 1528-7033. DOI: 10.1080/07380569.2013.76894 
82 KALAMATIKA, Volume 6, No. 1, April 2021, pages 71-82 